\title{
Effects of Abrasive Grit Shape on Grinding Performance
}

\author{
Xun Chen ${ }^{1}$, Lijun $\mathrm{Li}^{2}$, Qiaoping $\mathrm{Wu}^{3}$ \\ ${ }^{1}$ General Engineering Research Institute, Liverpool John Moores University, Liverpool, UK \\ ${ }^{2}$ College of Mechanical and Power Engineering, China Three Gorges University, Yichang, China \\ ${ }^{3}$ College of Mechanical and Electrical Engineering, Hunan University of Science and Technology, Xiangtan, China \\ 1‥chen@ljmu.ac.uk, ${ }^{2}$ 1lj@ctgu.edu.cn, ${ }^{3}$ meishanzi11@sina.com
}

\begin{abstract}
The quality of grit in grinding wheel has predominate influence on the grinding wheel performance, such as wheel sharpness and wheel wear. This paper presents an investigation on the effect of difference grit shapes on grinding force and grit holding capacity. Some critical grinding behaviours are analysed in relation to grit shapes to establish a foundation for grit quality assessment. A desirable grit shape is identified for better cutting efficiency and grinding wheel life.
\end{abstract}

Keywords - Grinding; Grit shape; Slip-line theory; Finite element method.

\section{INTRODUCTION}

Grinding is one of the main methods of precision machining. Grinding performance is often assessed by grinding force, energy consumption, wheel wear, ground workpiece geometry accuracy and surface integrity. As a dominated influential parameter, the grinding force depends on the shape and cutting depth of each engaged active grit, which are of random nature of distribution and orientation. Traditionally, grinding force is analysed by determining "average" grit behaviour and its variation from the average so as to predict how the whole process behaves. The nature of the overall grinding system must be examined to explain grinding behaviour in terms of idealized single grits [1]. In order to assess abrasive grit quality in relation to grinding behaviour, the influences of grit shape on grinding force and grit holding capacity are critical for the improvement of grinding process.

Premature grit pullouts often happen during grinding because the bonding strength to the grits is insufficient [23]. In order to increase the bonding strength, the traditional method is to increase bond materials, but it has a negative impact on the chip moving space during grinding [4]. In the earlier studies, Malkin pointed out that bond fracture at the grain-bond junction reduces the wheel life significantly, which should be minimized [5], and further investigations have explored that stress concentration is the main factor that result in bond fracture during grinding [6-7]. Zhou et al [8] used a two-dimensional finite element model to analyze the stresses at the grain-matrix interface. The results show that a high stress state occurs at the interface close to the surface of the matrix, the magnitude of stress at the tension side of the particle increases drastically when the matrix is worn away evenly on both sides of the particle. Ding et al [9] developed a two dimensional finite element model to investigate the stress characteristics and fracture wear of the grains, it was found that grain macro-fracture wear is dominated by the brazing stresses in the junction region of the grains, and the peak brazing stress reduces with the increase in the grain embedding depth. However, the effect of grit shape on the stress was overlooked.

The purpose of this work is to analyze the effects of grit shape on grinding force and the stress in the bonding materials of the grinding wheel so as to establish a foundation for grit quality assessment. In this paper the influence of grit shape on grinding force is analysed by using slip-line method and the grit holding capacity is assessed by using finite element method.

\section{SLIP-LINE FIELD FORCE MODELLING}

\section{A. Slip-line field theory of abrasive grinding deformation}

One of simple methods for machining analysis is the slip-line field approach, which is used to model plastic deformation in plane strain only for a solid that can be represented as a rigid-plastic body. In terms of applications, the approach now has been largely superseded by finite element modelling $[10,11]$, which is not constrained in the same way and the complex loading (including static and dynamic forces plus temperature variations) can be considered. Nonetheless, slip line field theory can provide simple straight analytical solutions to a number of metal forming processes, and it utilises plots showing the directions of maximum shear stress in a rigid-plastic body which is deforming plastically in plane strain. These plots show anticipated patterns of plastic deformation from which the stress and strain fields in grinding can be estimated [12-16].

In principle, a valid slip-line field solution can be used to indicate the forces and energy involved in abrasive machining and it provides valuable insight into the nature of material flow processes and the effect of friction at the grit-workpiece interface. Challen and Oxley made a major contribution to understanding this in 1979 [17]. Three models of deformation were proposed taking account of the differences in material behaviour with different levels of roughness and varying effectiveness of lubrication. The Challen and Oxley models are illustrated in Figures $1-3$ $[17,18]$. These three slip-line fields were described as (1) 'wave of asperity deformation' corresponds to rubbing, (2) 
'wave removal' corresponds to ploughing and (3) 'chip formation' corresponds to cutting. Which type of field applied was a function of the attack angle of the wedge, $\alpha$, the shear strength of the interface of film, $\tau$, and the flow stress of the soft materials, $\mathrm{k}$, [19].

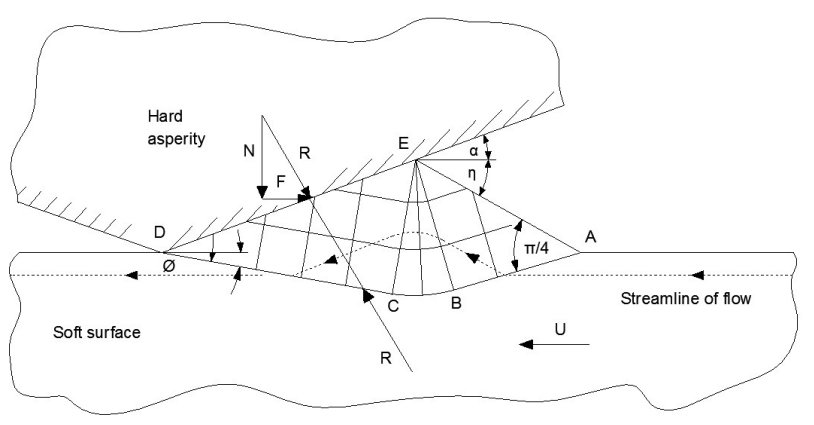

Figure 1. Wave model of asperity deformation

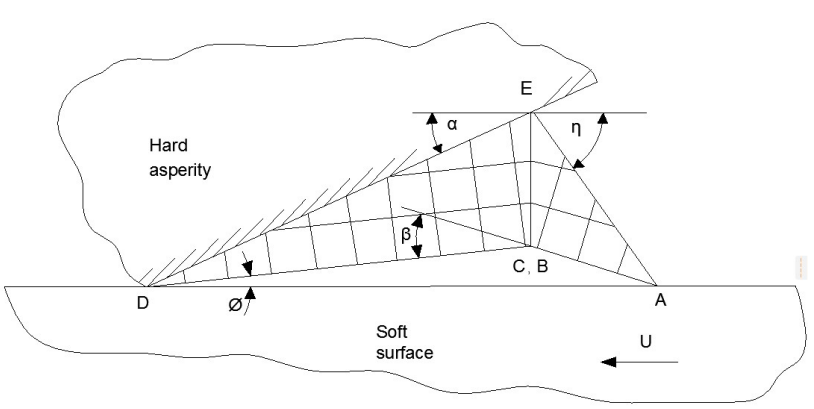

Figure 2. Wave removal model

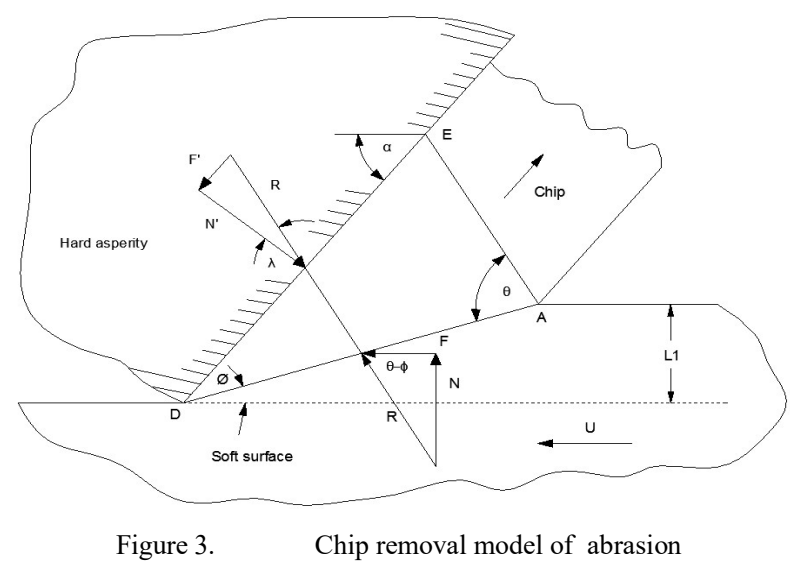

\section{B. Wave model of rubbing}

For a hard abrasive grit with a small attack angle $\alpha$ as illustrated Figure 1, material deformation was moves along the surface without material removal, as in the drawing and extrusion processes. This deformed layer of materials can be considered as a deformation flowing film. The friction angle at the asperity interface is

$$
\gamma=\alpha+\emptyset=\frac{1}{2} \cos ^{-1} f
$$

The slip lines meet at a free surface at $45^{\circ}$ for the maximum shear stress, so that

$$
\eta=\sin ^{-1}\left(\frac{\sin \alpha}{\sqrt{1-f}}\right)
$$

By defining the strength of the interfacial film as $f=$ $\tau / k$, where $\tau$ is the shear strength of the film and $k$ is the flow stress of the soft material $(0 \leq f \leq 1)$. Considering the results based on slip-line field geometry and stress relations illustrated in Fig.1, the force per unit width on the surface are found by resolving the stresses into the direction normal and parallel to the motion and multiplying by the contact length DE.

$$
\begin{aligned}
& F=k \cdot D E\left\{\cos (\alpha+2 \phi)+\left(1+\frac{\pi}{2}+2 \phi-2 \eta\right) \cdot \sin \alpha\right\} \\
& N=k \cdot D E\left\{\sin (\alpha+2 \phi)+\left(1+\frac{\pi}{2}+2 \phi-2 \eta\right) \cdot \cos \alpha\right\}
\end{aligned}
$$

where $F$ and $N$ are frictional and normal forces per unit width respectively.

\section{Chip removal models of abrasion}

The simplest chip removal model adopted by Challen and Oxley was an early model introduced by Lee and Shaffer [20] as illustrated in Figure 3. It is assumed that a chip is produced by a shock line of velocity continuity along the line $\mathrm{AD}$. After crossing the line $\mathrm{AD}$, the material has an upward velocity forming chips. The line AD is also called a slip line. The direction of the line AD is given by the angle at which a slip line meets the friction face DE of the asperity. From Mohr's stress circle, the direction is defined by

$$
\gamma=\alpha-\emptyset=\frac{\pi}{2}-\frac{1}{2} \cos ^{-1} f
$$

where $\alpha$ is the inclination angle of DE, $\varnothing$ is the angle of the slip line $\mathrm{AD}$, and $f$ is the friction factor given by $f=\tau / k$. The line $\mathrm{AE}$ is the stress free and, therefore, the slip line $\mathrm{AD}$ is at $45^{\circ}$ to $\mathrm{AE}$, i.e. $\theta=45^{\circ}$. The force ratio is given by

$$
\mu=\tan \left(\alpha-\frac{\pi}{4}+\frac{1}{2} \cos ^{-1} f\right)
$$

\section{Force prediction of abrasive grit}

A consistent physical modelling of the grinding process must begin from the basic physics of the grinding process with the consideration of the interaction of individual abrasive grit with the workpiece, and then be expanded to the behaviour of the whole grinding wheel. Since the geometry of grits is random, the grit shape has to be approximated by a few specific geometry to simplify the mathematical modelling of the individual grit interaction.

In this study, the abrasive grit shapes are classified into four groups, i.e. spherical, ellipsoid, pyramid and frustum pyramid. Figure 4 shows these four types of grits. In the analysis, the mean size of these grits is set as $50 \mu \mathrm{m}$, and the cut depth of penetration is $2 \mu \mathrm{m}$. Because the radius of curvature of spherical and ellipsoid girts are much bigger than the cut depth of grits, this situation can be assumed in accord with the slip-line wave model, and because the slop of frustum and pyramid is much bigger than $45^{\circ}$, the situation can be assumed in accord with the chip removal model. 
(a)

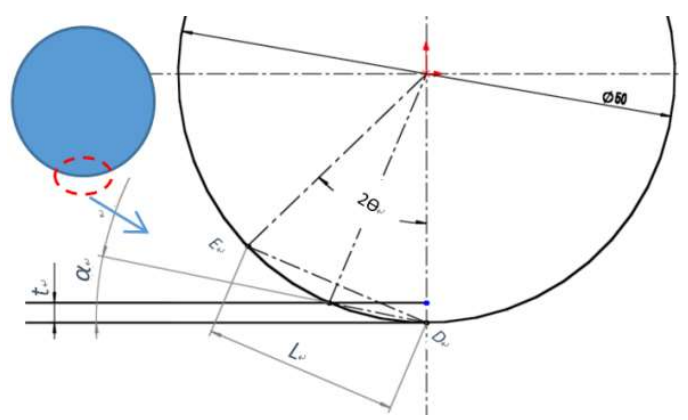

(b)

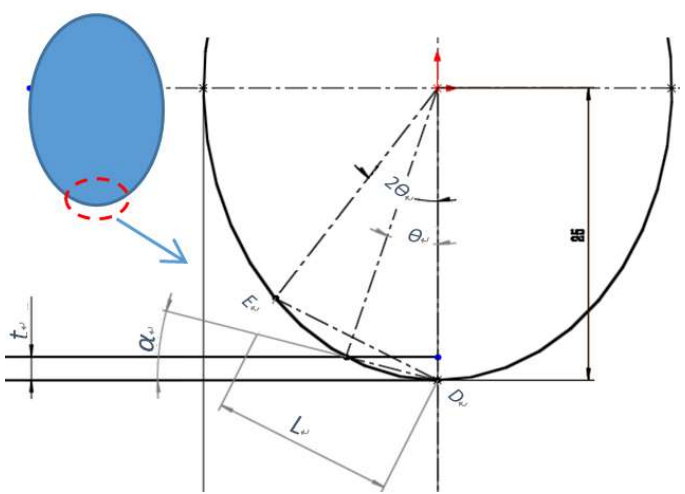

(c)

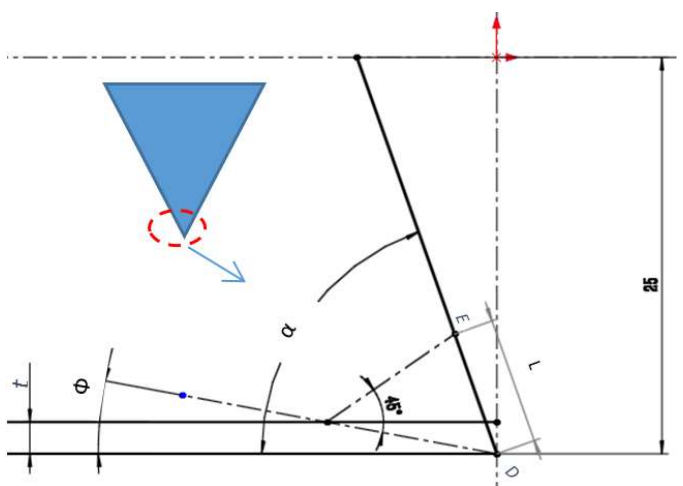

(d)

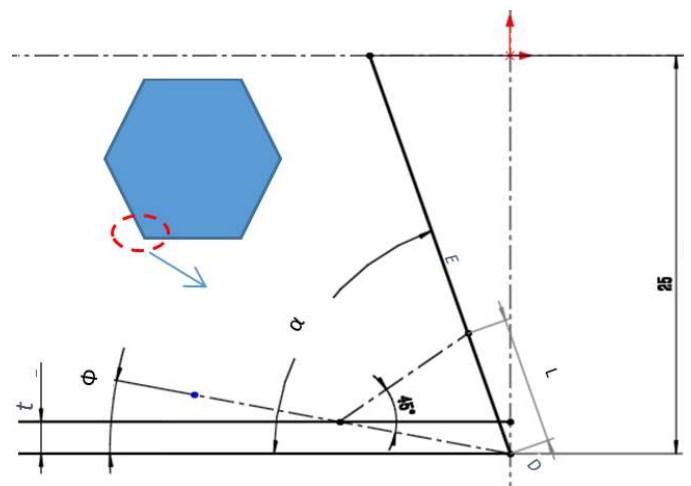

Figure 4. Simply model of abrasive grit shape

In the former situation, the attack angle $\boldsymbol{\alpha}$ can be obtained by taking account of the cut depth of grits and using the chord plane instead of the arc of circle and ellipse, while in the latter, the attack angle $\boldsymbol{\alpha}$ can be obtained directly through the slop of the grit shape in orthogonal plane. The friction coefficient $\boldsymbol{f}$ is assumed 0.5 , and the other parameters, such as $\boldsymbol{\phi}, \boldsymbol{\eta}$ and the length of DE, used for slip-line modelling are deducted according to the Equations
(1), (2) and geometrical relationship in Figure 4. The values of relevant parameters are listed in Table I.

With the values of $\alpha, f, \phi, \eta$ and DE deduced from slip-line models, equations (3) and (4) give the corresponding frictional force $F$, normal force $N$ and other relevant parameters as shown in Table II. The results show that pyramid shape grit gives the lowest grinding force and the sphere grit gives the highest force. The cutting forces of ellipsoid and frustum pyramid grits are lain between the pyramid and sphere. The high normal forces presented by sphere and ellipsoid grits are due to their high negative rake angles.

TABLE I. GRIT SHAPE AND PARAMETERS

\begin{tabular}{|l|l|l|l|l|l|l|l|}
\hline $\begin{array}{c}\text { Grit } \\
\text { shape }\end{array}$ & $\begin{array}{c}\text { Grit } \\
(\mu \mathrm{m})\end{array}$ & depth & $\boldsymbol{\alpha}$ & $\boldsymbol{f})$ & $\boldsymbol{\phi}$ & $\boldsymbol{\eta}$ & $\boldsymbol{D E}$ \\
$($ rad $)$ & $\boldsymbol{f}$ & $(\mathrm{rad})$ & $($ rad $)$ & $(\boldsymbol{\mu m})$ \\
\hline Sphere & 50 & 2 & 0.20 & 0.5 & 0.32 & 0.28 & 19.6 \\
\hline Ellipsoid & 50 & 2 & 0.25 & 0.5 & 0.27 & 0.35 & 15.55 \\
\hline Frustum & 50 & 2 & 1.17 & 0.5 & 0.12 & 1.28 & 12.0 \\
\hline Pyramid & 50 & 2 & 1.23 & 0.5 & 0.18 & 1.46 & 8.0 \\
\hline
\end{tabular}

TABLE II. GRINDING FORCE

\begin{tabular}{|c|c|c|c|c|l|}
\hline $\begin{array}{c}\text { Grit } \\
\text { shape }\end{array}$ & $\begin{array}{c}\text { Shear } \\
\text { stress } \\
(\mathbf{M P a})\end{array}$ & $\begin{array}{c}\text { Normal } \\
\text { stress } \\
(\mathbf{M P a})\end{array}$ & $\boldsymbol{F}$ & $\boldsymbol{N}$ & $\begin{array}{c}(\mathbf{N} / \mathbf{m}) \\
\text { coefficient } \\
\text { of friction } \\
\boldsymbol{\mu}\end{array}$ \\
\hline Sphere & 458.61 & 1211.42 & 8898.72 & 23743.81 & 0.38 \\
\hline Ellipsoid & 486.30 & 1107.36 & 7561.99 & 17219.48 & 0.44 \\
\hline Frustum & 709.31 & 553.97 & 8511.68 & 6647.7 & 1.28 \\
\hline Pyramid & 742.07 & 509.25 & 5914.29 & 4058.7 & 1.46 \\
\hline
\end{tabular}

\section{GRIT HOLDING CAPACITY ANALYSIS}

Consider the situations that grinding wheels are made with diamond grits of four different shapes (spherical, pyramidal, ellipsoidal and polyhedral grits) of the maximum diameter of $50 \mu \mathrm{m}$ imbedding in the bond material $\mathrm{Cu}-\mathrm{Sn}-\mathrm{Ti}$ alloy. The properties of bond materials are taken from published literatures or supplied by the manufacturers, as listed in table III [9]. Commercially available 3D finite element program-SIMULATION of the SOLIDWORKS was used to analyse the stress exits in the bond material under the same workload. Threedimensional finite element models are established to investigate the effects of shapes of grain on the stresses and strains distribution around grits. Around $1 / 3$ of grit is imbedded in the bonding materials. The simulation applies normal force $\mathrm{Fn}$ of $0.04 \mathrm{~N}$ and the tangential force $\mathrm{Ft}$ of 
$0.02 \mathrm{~N}$ on the grain vertex region, i.e. the contact zone between the grit and the workpiece. The maximum stresses and strains in bonding materials for each grit shape are listed in Table IV.

TABLE III. MATERIAL PROPERTIES USED IN THE FEM ANALYSIS

\begin{tabular}{|c|c|c|}
\hline \multirow{2}{*}{ Property } & \multicolumn{2}{|c|}{ Material } \\
\cline { 2 - 3 } & Diamond & $\mathrm{Cu}-\mathrm{Sn}-\mathrm{Ti}$ \\
\hline Young's modulus E (GPa) & 1050 & 113 \\
\hline Poisson's ratio & 0.07 & 0.29 \\
\hline Thermal expansion coefficient $\left(10^{-6} \mathrm{~K}^{-1}\right)$ & 0.56 & 18.3 \\
\hline Yield strength (MPa) & 9000 & 245 \\
\hline Mass density (g.cm $\left.{ }^{-3}\right)$ & 3.52 & 8.23 \\
\hline
\end{tabular}

TABLE IV. MATERIAL PROPERTIES USED IN THE FEM ANALYSIS

\begin{tabular}{|l|l|l|}
\hline \multicolumn{1}{|c|}{ Grit shape } & Maximum stress (MPa) & Maximum strain (MPa) \\
\hline Sphere & $9.473 \times 10^{7}$ & $7.376 \times 10^{-4}$ \\
\hline Ellipsoid & $1.239 \times 10^{8}$ & $7.529 \times 10^{-4}$ \\
\hline Polyhedral & $3.042 \times 10^{8}$ & $1.825 \times 10^{-3}$ \\
\hline Pyramid & $1.224 \times 10^{9}$ & $5.047 \times 10^{-3}$ \\
\hline
\end{tabular}

Fig. 5 shows the stress distribution in the grain-bond junction region for different shapes of the diamond grains, it can be seen that the maximum stress occurred in the contact zone of the grit and workpiece. The maximum stress of the pyramidal grains is approximately $1.107 \times 10^{9}$ $\mathrm{Pa}$, while the shear strength of Cu-Sn-Ti alloy is $2.45 \times 10^{8}$ $\mathrm{Pa}$, it indicates that shear failure will occur in the contact zone, the macro-fracture at the grit-bond junction region will occur severely, which could lead to the grit pullout during grinding. The maximum stress of the polyhedral, ellipsoidal and spherical grains are approximately $2.56 \times 10^{8} \mathrm{~Pa}, 1.386 \times 10^{8} \mathrm{~Pa}$ and $9.307 \times 10^{7} \mathrm{~Pa}$ respectively. Fig. 6 shows the strain distribution in the grit-bond contact region for different shapes of the diamond grits, which indicates that the strains distribution have the same trend, the maximum strain of the pyramidal, polyhedral, ellipsoidal and spherical grains are $4.343 \times 10^{-3}, 8.639 \times 10^{-}$ ${ }^{4}, 7.227 \times 10^{-4}$ and $6.798 \times 10^{-4}$. At the same conditions, the bond strength of the spherical grain is most efficient during the grinding process, and the grains are not easily to fall off from the wheel surface. Therefore, the spherical grains is suitable for the preparation of diamond grinding wheel in terms of holding capacity.

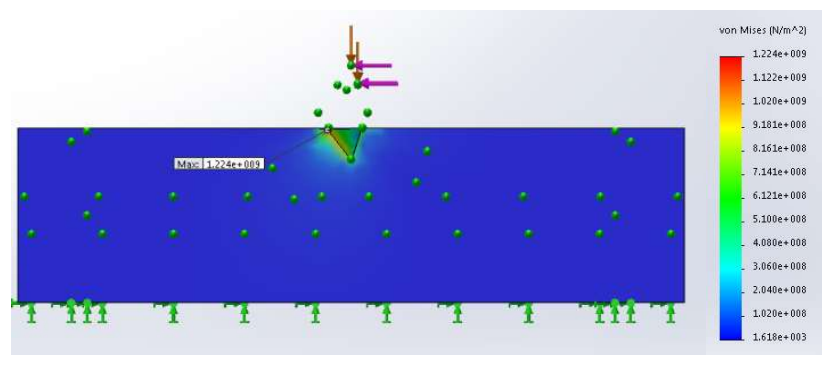

(a) Pyramidal

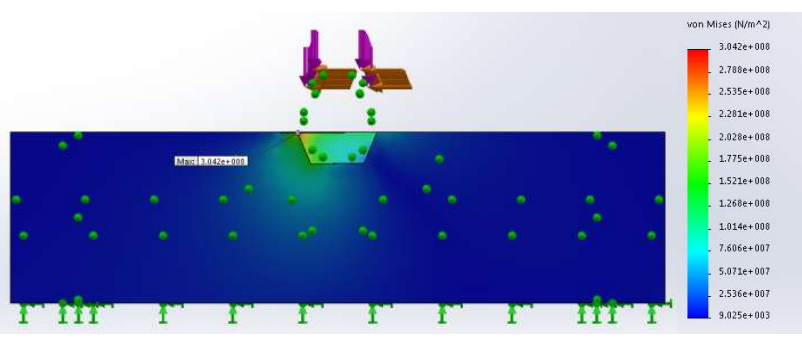

(b) Polyhedral

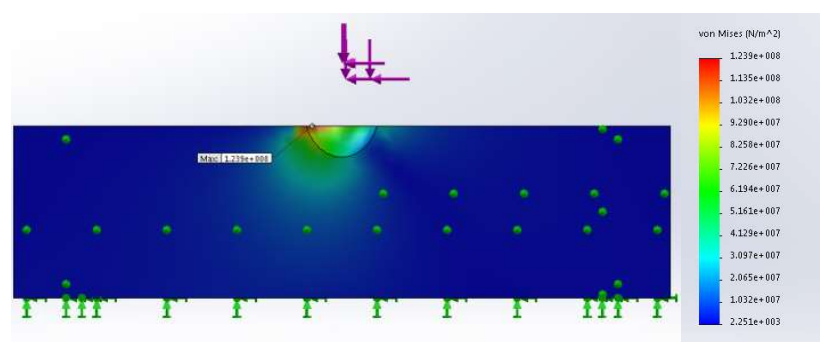

(c)Ellipsoidal

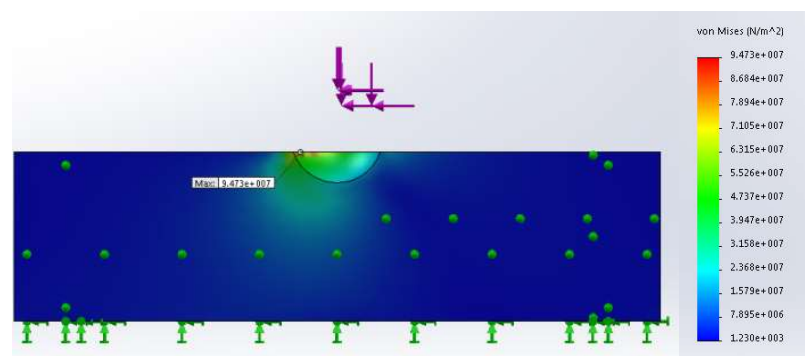

(d) Spherical

Figure 5. Bonding stress distribution for different shape grits

\section{CONCLUSION}

The investigation shows significant influence of grit shape on grinding behaviours in terms of grinding force and grit holding capacity. The analysis results in the paper show:

1. Pyramidal grits possess sharp cutting edges, which gives lowest cutting forces. However the cutting width 
of pyramidal grit is small, which may not give best cutting efficiency. Further investigation is required to understand the grit cutting width influences.

2. The grit shapes have a great influence on the stress distribution in the grain-bond junction region. Under the same workload, the maximum stress of grit holding in descending order is pyramidal, polyhedral, ellipsoidal and spherical grits. This means the spherical shape grit possesses better bonding strength the other grits.

Therefore, it might conclude that a bulky spherical grit with large attacking angle could be a desired grit shape.

\section{REFERENCES}

[1] Ioan D. Marinescu, W. Brian Rowe, Boris Dimitrov, Hitoshi Ohmori, 2013. Tribology of Abrasive Machining Processes (Second edition). Elsevier Inc.

[2] J.C.Sung, M.Sung. The brazing of diamond, International Journal of Refractory Metals \& Hard Materials, 2009,27:382-393

[3] B. J. Sun, B. Xiao, S. X. Liu. Microstructure and performance of diamond abrasive grains brazed in mesh belt furnace with ammonia dissociating atmosphere, Int. Journal of Refractory Metals and Hard Materials, 2016, 60:154-159

[4] G. F. Zhang, B. Zhang, Z. H. Deng. Recent adavances and future perspective in grinding wheel structure, International Journal of Abrasive technology, 2009, 2:113-128

[5] S. Malkin, N.H.Cook. The wear of grinding wheels:Part 2Fracture wear, Journal of Engineering for Industry, 1971, 93:1129-1133

[6] J. Badger. Factors affecting wheel collapse in grinding, CIRP Annals-Manufacturing technology, 2009, 58:307-310

[7] T. Yamaguchi, M. Higuchi, S. Shimada, .et al. Fractal modeling for 3D structure of vitrified-bonded wheel, Precision Engineering, 2007, 31:40-46

[8] Y. Zhou, P. D. Funkenbusch, D. J. Quesnel, Stress distributions at the abrasive-matrix interface during tool wear in bound abrasive grinding-a finite element analysis, wear, 1997,209,247-254

[9] W. F. Ding, J. H. Xu, Z. Z. Chen,et al. Interface characteristics and fracture behavior of brazed polycrystalline CBN grains using $\mathrm{Cu}-\mathrm{Sn}$-Ti alloy, Materials Science and Engineering, 2013, 559:629-634

[10] J. Mackerle, Finite-element analysis and simulation of machining: a bibliography,Journal of Materials Processing Technology, 1999,83:17-44

[11] Dinesh Setti, Benjamin Kirsch, J. C. Aurich, An analytical method for prediction of material deformation behavior in grinding using single grit analogy, Procedia CIRP, 2017, 58: $263-268$

[12] W. Lortz. A Model of the Cutting Mechanism in Grinding., Wear ,1979,53: 115-128

[13] A. A. Torrance, T. T. Buckey. A slip-line field model of abrasive wear, Wear, 1996,196: 35-45

[14] Xun Chen and W. Bran Rowe. Analysis and simulation of the grinding process. Part II: Mechanics of Grinding,Tools Manufact. 1996, 36: 883-896

[15] N Fang, I. S. Jawahir, P. L. B. Oxley. A universal slip-line model with non-unique solutions for machining with curled chip formation and a restricted contact tool, International Journal of Mechanical Sciences, 2001, 43: 557-80

[16] N. Fang, Slip-line modeling of machining with a roundededge tool - Part I: new model and theory, Journal of the Mechanics and Physics of Solids, 2003, 51: 715 - 742
[17] J.M. Challen, P. B. Oxley, An explanation of the different regimes of friction and wear using asperity deformation models, Wear, 1979, 53: 229-243

[18] A. J. Black, E. M. Kopalinsky, P. L. B. Oxley, Asperity deformation models for explaining the mechanisms involved in friction and wear-a review, Proc. Inst. Mech. Eng, 1993,207:335-353

[19] J. A. Badeger, A.A. Torrance, A comparison of two models to predict grinding forces from wheel surface topography, Int. J. Mach. Tools Manufact, 2000, 40:1099-1120

[20] E. H. Lee, B. W. Shaffer. The Theory of Plasticity Applied to a Problem of Machining, Trans, ASME, 1951,73:405-413

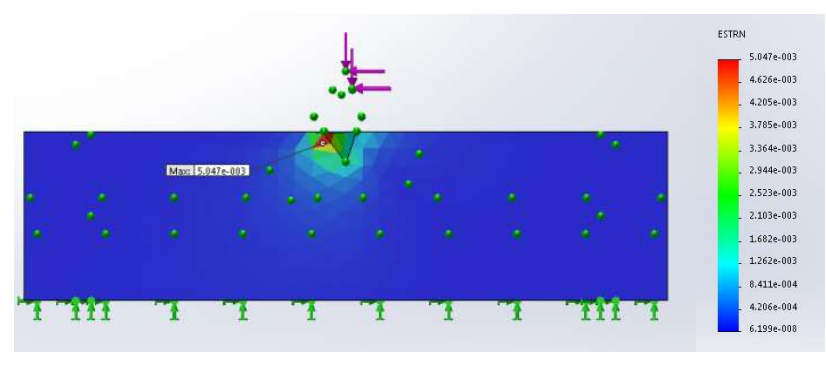

(a) Pyramidal

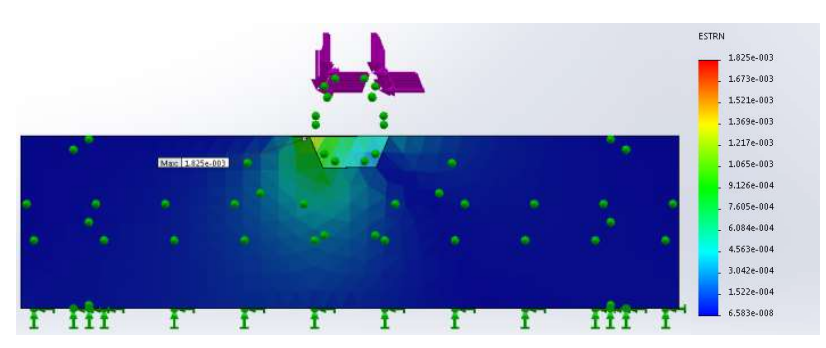

(b) Polyhedral

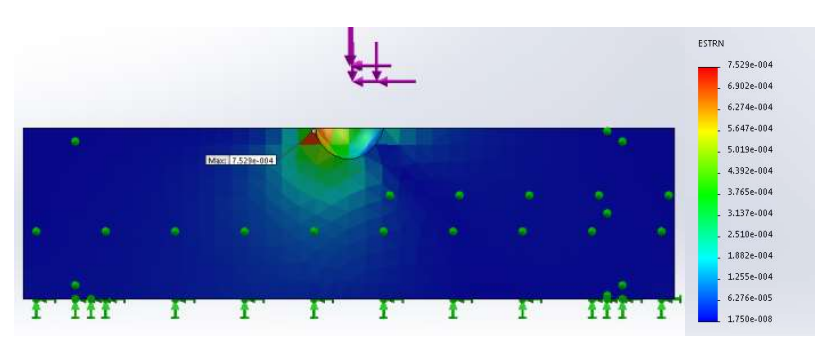

(c)Ellipsoidal

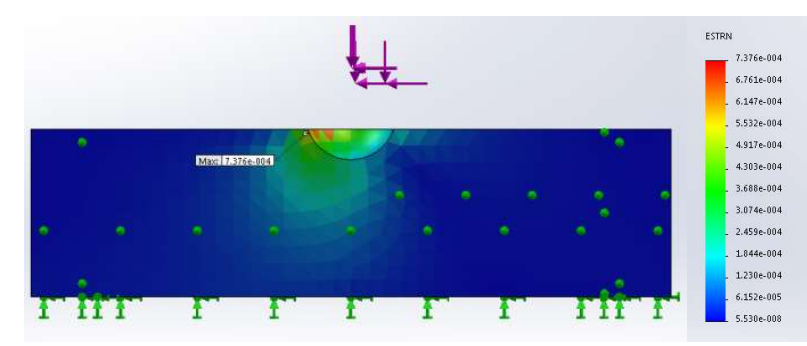

(d) Spherical

Figure 6. Bonding material strain distribution for different shape grits 